
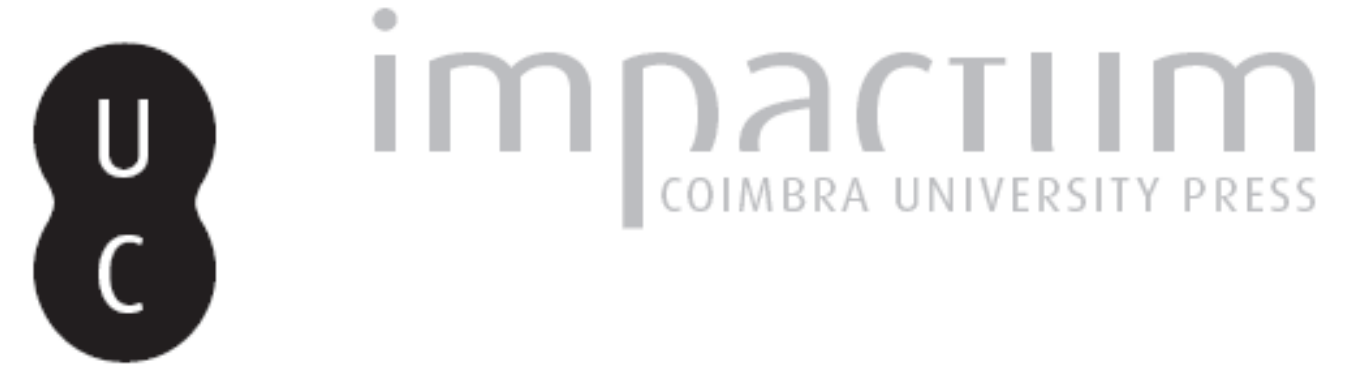

O ambiente (urbano): um instrumento de concretização de penas vs um Ecossistema cujas vulnerabilidades urge conhecer
Autor(es):
Monteiro, Ana

Publicado por: Associação Portuguesa de Riscos, Prevenção e Segurança

URL persistente:

URI:http://hdl.handle.net/10316.2/40143

DOI:

DOI:https://doi.org/10.14195/1647-7723_4_2

Accessed : $\quad$ 26-Apr-2023 08:02:58

A navegação consulta e descarregamento dos títulos inseridos nas Bibliotecas Digitais UC Digitalis, UC Pombalina e UC Impactum, pressupõem a aceitação plena e sem reservas dos Termos e Condições de Uso destas Bibliotecas Digitais, disponíveis em https://digitalis.uc.pt/pt-pt/termos.

Conforme exposto nos referidos Termos e Condições de Uso, o descarregamento de títulos de acesso restrito requer uma licença válida de autorização devendo o utilizador aceder ao(s) documento(s) a partir de um endereço de IP da instituição detentora da supramencionada licença.

Ao utilizador é apenas permitido o descarregamento para uso pessoal, pelo que o emprego do(s) título(s) descarregado(s) para outro fim, designadamente comercial, carece de autorização do respetivo autor ou editor da obra.

Na medida em que todas as obras da UC Digitalis se encontram protegidas pelo Código do Direito de Autor e Direitos Conexos e demais legislação aplicável, toda a cópia, parcial ou total, deste documento, nos casos em que é legalmente admitida, deverá conter ou fazer-se acompanhar por este aviso.

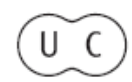




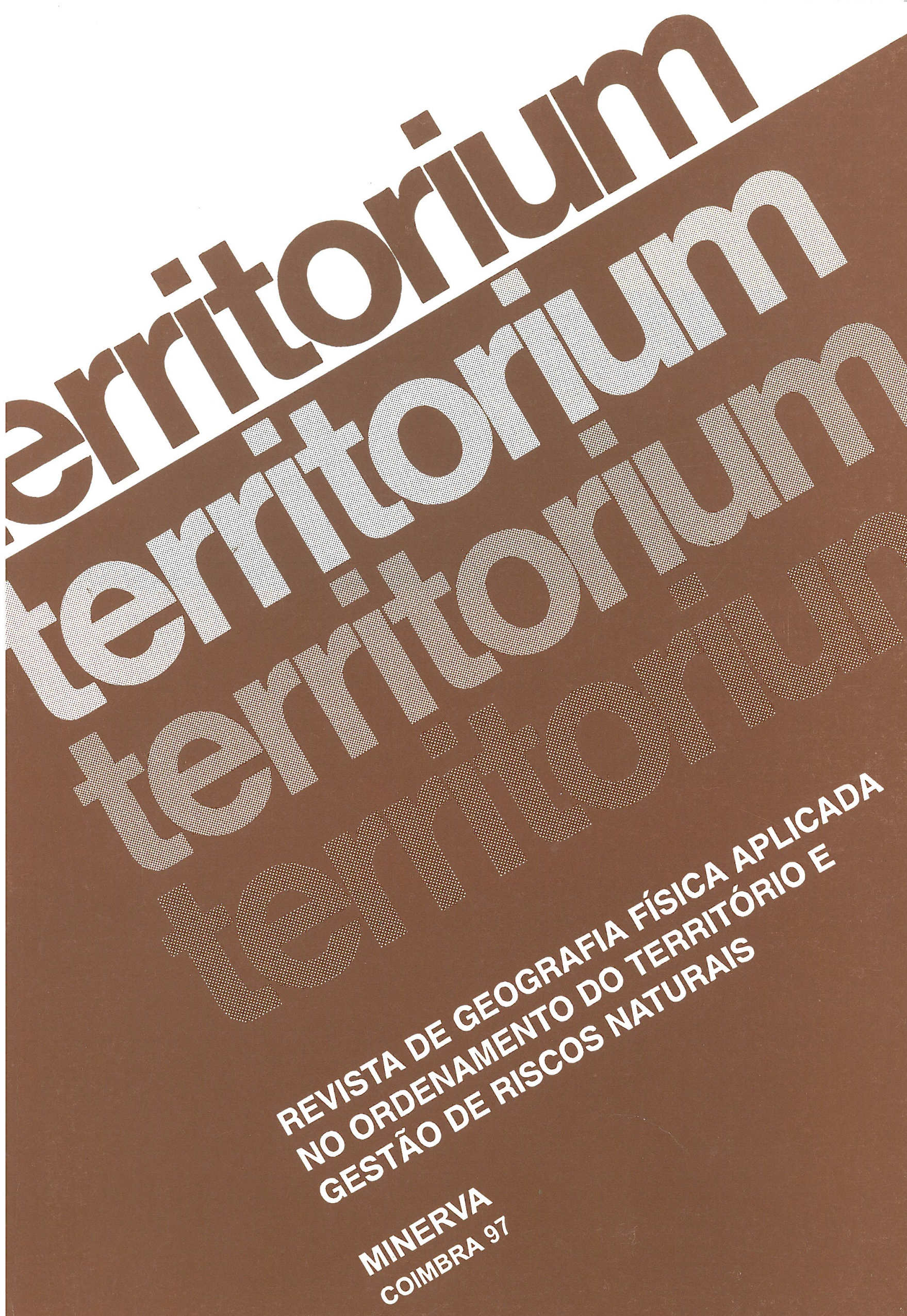




\title{
O Ambiente (Urbano): um instrumento de concretização de penas vs um Ecossistema cujas vulnerabilidades urge conhecer
}

\author{
Ana Monteiro*
}

\begin{abstract}
Resumo:
O presente artigo debruça-se sobre o estado do ambiente em Portugal e, em particular, sobre as "rotas de colisão" entre sustentabilidade do ambiente natural e expectativas de qualidade de vida dos habitantes dos espaços urbanizados, mostrando como alguns dos problemas existentes se relacionam com certos aspectos da cultura judaico-cristã que nos marca desde há séculos. Propõe-se uma abordagem geográfica dos ecossistemas urbanos de modo a encontrar explicações científicas e sugerir soluções para melhorar a qualidade de vida dos cidadãos. Palavras chave:

Ecossistema urbano, sustentabilidade do ambiente natural, expectativas de qualidade de vida, tradição judaico-cristã.
\end{abstract}

\section{Résumé:}

Dans cet article on présente l'état de l'environnement au Portugal et, particulièrement, les "routes de collision" entre la soutenabilité de l'environnement naturel et les expectatives de qualité de vie des populations des espaces urbanisés, en montrant comment certains des problèmes qui se posent sont en rapport avec quelques aspects de la culture judaique-chrétiènne marquante depuis des siècles. On propose l'étude géographique des écosystèmes urbains ayant comme finalité trouver des explications scientifiques et de suggérer des solutions pour améliorer la qualité de vie des citoyans.

Mots clés:

Ecosystèmes urbains, soutenabilité de l'environnement naturel, expectatives de qualité de vie, tradition judaïque-chrétiènne.

\begin{abstract}
:
The aim of this article is the state of the environment in Portugal, particularly some "routes of collision" between natural environment sustainability and the urbanized people expectations of life quality, showing that some existing problems are related with aspects of judaic-christian culture present here for centuries. In order to obtain scientific explanations and to give a better quality of life to citizans the Author proposes the geographical study of urban ecosystems.

Key words:

Urban ecosystems, sustainability of natural environment, expectations of life quality, judaic-christian tradition.
\end{abstract}

\section{Introdução}

A maioria das aglomerações urbanas portuguesas, à semelhança do que acontece noutros países, atravessa, neste momento, um processo de necrosamento e desinteresse acelerado, despoletado pela perda progressiva de vantagens comparativas. Os modelos de organização espacial existentes revelaram-se incapazes de fazer face às actuais necessidades dos principais agentes económicos e às expectativas dos cidadãos-residentes.

A degradação da qualidade do ar, as modificações no balanço energético, a diminuição do conforto, da qualidade de vida e do bem-estar, o incremento de processos de marginalização social ou a insegurança

* Instituto de Geografia. Faculdade de Letras. Universidade do Porto. são, apenas alguns exemplos da(s) incapacidade(s) das cidades portuguesas para responder aos novos modelos de desenvolvimento económico. Esta perda de competências foi transformando este tipo de aglomerados em espaços (aparentemente!) sem futuro (Fig. 1).

Todavia, a imaginação e criatividade dos investigadores e dos decisores para encontrar outros "modos de organização territorial de sucesso" (FERRÃO, 1991), onde fosse possível concentrar as actividades produtivas, os laboratórios, os centros de pesquisa, os espaços de cultura, de lazer, etc., que facilitasse a difusão das inovações e intensificasse as sinergias necessárias aos novos modelos económicos, não surtiu os efeitos almejados. Desta incapacidade resultou a constatação de que afinal as cidades, se reavivadas e requalificadas, continuam a ser um dos arranjos espaciais mais atractivos e potencialmente mais eficazes. 
As cidades são espaço sem futuro?...

A concorrência deixou dc assentar mas condiçōes de produção e passcru à depender da :

- criatividade, nexibilidade de produção, equipamentos de usos múltiplos, cultura artesanal iniciativa do trabalhador dentro da cmpresa, inovação tecnologica, proximidade entre Cenırus de Investigação-Indústria-Serviços de Apoio,etc.....

As cidares continuam a ter futuro porque

multiplicam e petenciam problemas económicos, sociais, ambientais mas também talentos

Contintam is ter Vantagens?.....

1) Económicas - é mais baralo dolar de serviços e infracstruturas um grupo concentrado de pessous

2) Psico-Saciais- liberdade individual (anonimalo), maior diversidade de estímulos, maior fertilizaçä́o cruzada de ideias (geradoras de energia, vitalidade, cıc), major diversidade de mầ-de-obra com graus de qualificaçũo diferenciados (actividades exotéricus), maior holerîncti e compreensĩo, maior diversidade de molos de vida, maior facilidade de comunicaȳāo, elc.

Fig. 1 - Vantagens e constrangimentos dos modelos de organização espacial urbanos.

Contudo, os espaços urbanos terão de se adequar a um novo papel, de modo a oferecer, para além da facilidade de comunicação e de um excelente quadro de acessibilidades, um enquadramentofísicoatractivo para uma população muito mais exigente em termos de qualidade de vida..

A necessidade de sedução, através da qualidade do meio ambiente, passou, portanto, a ser, para as aglomerações urbanas, tão importante como as suas capacidades/competências de oferta em redes de comunicação, diversidade funcional, clientela potencial, etc.

Os novos espaços de crescimento sobreviverão e desenvolver-se-ão consóante a sua capacidade de integrar, harmoniosamente, um aparelho sócio-produtivo muito mais exigente nos padrões de bem-estar e qualidade de vida.

A sua sobrevivência e vitalidade dependerá sobretudo do engenho e arte com que os decisores forem capazes de gerir os recursos naturais disponíveis e as expectativas de qualidade de vida dos cidadãosresidentes (Fig. 2).

\section{SUSTENTABILIDADE}

Factores Naturais \& Factores Humanos

Factores Naturais = recursos minerais, recursos energéticos, diversidade climálica, diversidade faunistica, diversidade florística, elc.

Factores Humanos = estrutura etária jovem, pepulaçāo activa qualificada, mão de obra com fonnação diversificada, situação periférica relativamente aos conflitos intenacionais, segurança, politica de colonização eficaz, organização econónica eficiente e estável, estabilidade política, etc

Fig. 2 - A gestão sustentável de espaços urbanizados.
Em Portugal, os padrões de bem-estar e qualidade de vida dos cidadãos urbanos não se repetem no norte, no sul, no litoral ou no interior. Divergem de acordo com a história, as memórias, os hábitos, o acesso à informação, o rendimento das famílias e as disponibilidades de recursos naturais na proximidade.

Por isso mesmo, a leitura e avaliação do património natural disponívele da sua apetência para ser carreado para a promoçăo do desenvolvimento sustentável de cada aglomeração urbana não basta por si só. É necessário entrecruzar o valor intrínseco dos recursos locais com a "consciência ecológica" e a "sensibilização eeducação ambiental" típicas dos cidadãos-residentes em cada região.

A avaliação dos recursos naturais mobilizáveis para o desenvolvimento exige um conhecimento prévio quer da multiplicidade de contextos históricos e sociais, quer das diversas perceptibilidades ambientais e aspirações, quanto aos limiares de conforto e bem estar de cada um dos grupos populacionais em causa.

A heterogeneidade topográfica e climática associada aos muitos séculos de história da ocupação do território nacional, explica a vastíssima gama de contextos geográficos em que, nos dias de hoje, emergem as aglomerações urbanas portuguesas.

Proliferam, em Portugal, cidades de dimensões variadas, com ciclos de vitalidade insistentemente arquivados no território e no património edificado e sobretudo com diversos sinais dos atributos que, em cada época histórica, serviram para rentabilizar e aumentar a sua capacidade de sedução.

A necessidade de consolidar no território nacional uma rede de espaços urbanizados que facilite a concretização da estratégia de desenvolvimento económico planeado, exige que se assuma à partida um compromisso entre os limiares de resistência $\mathrm{e}$ adaptabilidade do Homem e de outros seres vivos e a intensidade e magnitude dos impactes ambientais inevitáveis em qualquer processo massificado de ocupação e utilização do espaço, como acontece nas aglomerações urbanas.

Tal como sucedeu no passado, cada aglomeração urbana terá de procurar encontrar a melhor combinação possível entre os modos de criação de riqueza indispensáveis à sua sobrevivência enquanto núcleos de fixação de pessoase de atracção de investimento e a manutenção equilibrada dos recursos naturais existentes.

Este compromisso, embora frágil e complexo, é relevante. Contudo, a sua exclusão na definição das estratégias de ordenamento do território pode inviabilizar a médio e longo prazo a sobrevivência das cidades, quer enquanto espaços atractivos para a fixação dos Homens, quer enquanto cenário para o tipo de desempenho que se lhes exige neste virar de século - espaços aprazíveis, qualificados, saudáveis e confortáveis. 
É, portanto, fundamental encontrar a fórmula ideal de articulação entre a necessidade de introduzir medidas mais rígidas que permitam a manutenção do património natural, sobretudo quando os Ecossistemas são particularmente frágeis e vulneráveis e a sua existência se revela o potencial de atracção de maior significado para a cidade, e a delapidação controlada de alguns recursos naturais nos espaços em que $o$ número de pessoas e actividades é determinante para a viabilização de alguns investimentos.

Se é verdade que não é mais possível assumir uma postura ecocêntrica, de retorno às origens, à auto-suficiência, à reverência absoluta relativamente ao Ecossistema, totalmente contraditória com as inúmeras evidências da insistente preferência dos Homens pelo modelo de organização espacial em cidades, também é certo que o "modelo urbano" actual passou a incluir mais explicitamente a qualidade do ambiente como condição de sucesso.

A transformação dos centros urbanos em espaços mais aprazíveis para os residentes e utilizadores da cidade reforçando a capacidade para seduzir novos investidores implicará, sem dúvida, a manutenção de:

$1^{\underline{0}}$ uma rede de saneamento básico eficaz;

$2^{2}$ um sistema de recolha e tratamento de resíduos sólidos (domésticos e industriais) eficiente;

3" uma rede de distribuição de água para abastecimento público eficaz;

$4^{\text {" }}$ uma integração harmoniosa das diversas funções urbanas (produtiva, prestação de serviços, residencial, desportiva, lúdica e cultural);

$5^{\circ}$ um controle e gestão de todas as intervenções no tecido urbano no sentido de manter e preservar a Imagem desejada.

\section{O estado do ambiente em Portugal}

Em Portugal, assistimos actualmente, a uma profunda dicotomia entre uma vasta área do território nacional, identificada como de grande interesse para a conservação e valorização do património natural (511 000 ha correspondente a $6 \%$ do território nacional), onde a gestão do espaço está sujeita a fortes restrições do uso, e uma área, que na totalidade é muito menor, ocupada por aglomerações urbanas com mais de 2000 hab., onde reside mais de $50 \%$ da população portuguesa (>4500 $000 \mathrm{hab}$.), onde a promiscuidade de usos dificulta grandemente a implementação de uma política de desenvol vimento sustentável e gera cenários de absoluta e total insustentabilidade (Fig. 3 e 4).

Estas aglomerações urbanas (Fig.4) distribuem-se, quanto à qualidade do ambiente urbano, em dois grandes grupos: (i) as cidades do eixo litoral entre Braga e Setúbal onde se incluem as duas grandes metrópoles (Portoe Lisboa); (ii) as cidades de pequena e média dimensão.

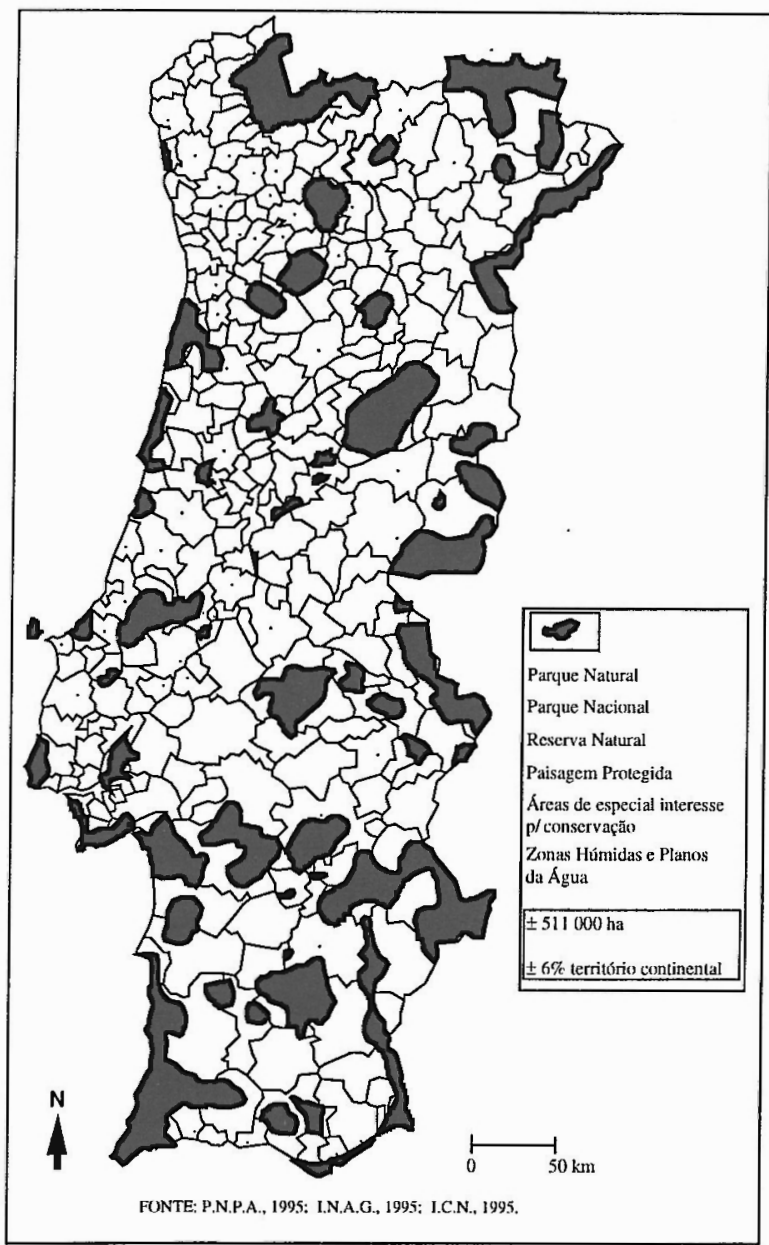

Fig. 3 - Delimitação simplificada das áreas de grande interesse para a conservação e valorização đo património natural em Portugal Continental.

As primeiras, confrontam-se actualmente com um vasta gama de carências associadas ao intenso e impreparado processo de urbanização que viveram nas últimas décadas.

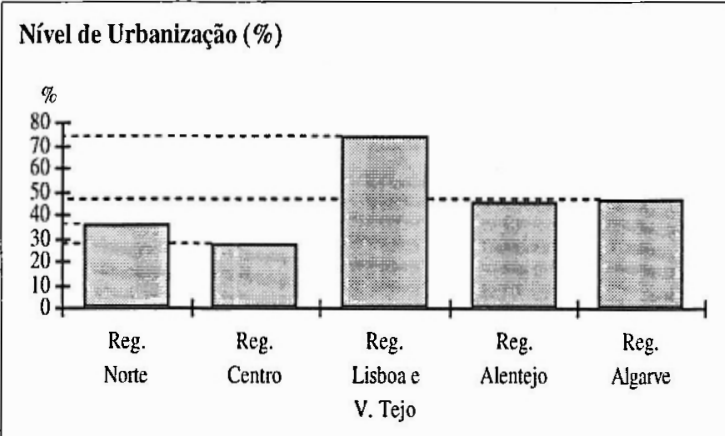

Em Portugal Continental, mais de 4500000 pessoas residem em lugares com mais de 2000 hab. ( $\pm 50 \%$ da população)

Fig. 4 - Níveis de urbanização em Portugal Continental (INE, 1995). 
Os estrangulamentos ao nível do abastecimento público de água, das soluções de recolha, deposição e tratamento dos resíduos sólidos, da drenagem e tratamento de esgotos, da degradação da qualidade do ar, repetem-se em quase todas.

A delapidação do património natural foi, na maioria dos casos, indiscriminada e intensa. Os impactes ambientais gerados são já, em grande número, irreversíveis.

O esforço, nestes casos, exige uma avaliação dos metabolismos urbanos em curso e a adopção de algumas operações de verdadeira cosmética que recrie, ainda que artificialmente, alguns mosaicos de conforto e bem-estar indispensáveis ao processo de reanimação destes espaços.

A presença próxima do mar e os incontáveis esforços de engenharia hidráulica mal sucedidos, para conter a sua presença nos limites artificiais planificados/desejados pelo Homem, são um excelente exemplo da incapacidade do Homem para antecipar, prever e controlar as relações de causalidade entre o tipo e intensidade de acções de origem antrópica e as respostas mais ou menos impulsivas e inesperadas dos sistemas naturais.

Este impacte preocupante associado à presença de um grande número de aglomerações urbanas perfeitamente consolidadas e estruturantes para o desenvolvimento económico nacional, começa a evidenciar o sorvedouro de investimentos a que pode conduzir este tipo de irreverência face à geodinâmica litoral.

Apesar de ser cada vez mais frequente e admissível a polemização em torno da lógica de manutenção dos actuais índices de ocupação do solo nestas áreas, permanecem inúmeras dúvidas sobre a eficácia de outro tipo de ordenamento no que respeita à diminuição substantiva dos custos sistemáticos canalizados para as obras de protecção da orla costeira.

Neste tipo de aglomerações, a requalificação ambiental urge, mas passa pela definição de uma estratégia de maior harmonização entre as funções que tipificam qualquer espaço urbano - produtivas, lazer, educação, cultura, etc..

O património natural aindaemerso nas proximidades deste conjunto de aglomerações urbanas constitui como que um adereço mais ou menos longínquo apreciado de acordo com as necessidades lúdicas de cada ritmo de vivência urbana.

As segundas, pela sua dimensão e dinamismo, conservam ainda recortes significativos de paisagem de grande qualidade cénica, biótopos e sítios de grande valor ecológico quase virgens.

Apesar de proliferarem também alguns dos estrangulamentos ao nível das infraestruturas e equipamentos, a irreversibilidade dos impactes não é tão frequente. Oenquadramento geográfico associado à menor pressão sobre o espaço permite ainda, na maioria das cidades, mobilizar a qualidade e diversidade do património natural para a redinamização e consolidação destes espaços urbanizados.

Neste grupo, a promoção de uma estratégia de desenvolvimento sustentável é ainda facilmente concretizável desde que se compreenda que uma parte substantiva das suas competências passa pela visibilidade e valorização dos recursos naturais disponíveis.

\section{Os espaços urbanizados portugueses: que rotas de colisão entre a "sustentabilidade do ambiente natural" e as expectativas de "qualidade de vida" dos cidadãos?}

Apesar de tudo, os espaços urbanos portugueses têm vindo a evidenciar, cada vez com maior clareza, uma enorme capacidade de se reorganizarem e de se moldarem, através de uma diversidade de "respostas", às inúmeras acções de origem antrópica de que têm sido alvo.

A observação da plasticidade de um destes espaços, em particular - a cidade do Porto - tem-nos conduzido, enquanto geógrafos, a procurar compreender alguns dos nexos de causalidade existentes entre o Tipo de Metabolismo Urbano c a Capacidade de Resistência e Adaptabilidade dos Homens.

Experiências anteriormente encetadas no âmbito do conhecimento das possíveis relações de causa-efeito emergentes na análise do triângulo Clima-Poluição-Saúde(A.MONTEIRO, 1993), motivaram-nos a aprofundar, a actualizar e a prosseguir a compreensão dos Ecossistemas Urbanos ancorados numa perspectiva sistémica.

As relações de dependência entre o clima, a poluição e a saúde, para além de excelentes "indicadores desustentabilidade" do espaço urbano, revelaram-se um bom início de reflexão sobre o tipo de soluções práticas que urge encontrar, a fim de colocar na mesma direcção "sustentabilidade do ambiente natural" e "expectativas de qualidade de vida".

Ao questionarmo-nos sobre a motivação que conduz cada vez mais pessoas para áreas cujas características contrariam, pelo menos aparentemente, o cenário de "qualidade de vida" desejado pela maioria dos homens das sociedades modernas, ou o que leva os homens a preferirem a cidade cosmopolita à cidade média, ou ainda, a elegerem os espaços mais intensamente urbanizados às suas periferias, mais integradas no ambiente natural, menos desagradáveis, menos desqualificadas, menos inseguras, menos poluidas, enfim, mais saudáveis, verificamos que as prioridades da estratégia individual dos cidadãos está longe de coincidir com a lógica prevista pelos urbanistas, sociólogos, geógrafos, políticos, etc. 
As cidades possuem, de facto, virtudes que, ao longo dos séculos, evidenciaram ser incomparavelmente mais vantajosas do que que qualquer outro tipo de soluções organizativas, no espaço, de pessoas e actividades económicas (Fig. 1).

Numa época em que a "sustentabilidade", a "escassez de recursos naturais", a "delapidação do património natural", são temas obrigatórios no discurso científico, económico e político, é oportuno analisar o significado efectivo do conceito de "qualidade de vida", para o diverso e vasto tipo de cidadãos que continuam a ser atraídos pelo modus vivendi urbano - uma das organizações espaciais, cujo tipo e ritmo metabólico, deveria, pelo menos teoricamente, repelir e afastar os homens.

Se tal não acontece, mesmo numa época em que a informação/formação sobre as relações de causalidade entre a excessiva artificialização do suporte biogeofísico nas áreas urbanizadas e os reflexos negativos na saúde e bem-estar dos residentes se intensificou, então talvezpossamos deduzir que os homens continuam a atribuir essencialmente às cidades, o privilégio de serem o melhor veículo para a concretização dos seus objectivos de melhoria da sua "qualidade de vida".

Se assim é, então existe uma conflitualidade clara e latente entre o conceito teórico de "qualidade de vida" associado à "sustentabilidade do ambiente natural" e a definição na prática das opções dos cidadãos (dos mais variados estratos sócio-económicos) quanto ao quadro de referência desejado no que respeita ao preenchimento de parâmetros de qualidade para o espaço vivido.

Embora, do ponto de vista científico, não nos restem dúvidas sobre a inevitabilidade de alterar alguns comportamentos e atitudes de cidadania nos espaços urbanos, sob pena de continuarmos a agravar a intensidade e magnitude dos impactes ambientais negativos, a um ritmo cujas consequências não controlamos, do ponto de vista prático, torna-se cada vez mais evidente, que a "sustentabilidade ambiental" e a procura de melhor "qualidade de vida", não se traduzem necessariamente, em opções de localização ou de comportamento idênticas.

Esta insistente preferência dos cidadãos pelos espaços intensamente urbanizados é o paradigma explícito da dissonância existente nos quadros sócioculturais vigentes entre as expectativas de "qualidade de vida" e o "desenvolvimento sustentável".

A poluição atmosférica, a saúde pública, o ruído, a promiscuidade, a insegurança, a competitividade crescente, a escassez de espaços verdes/per capita, o aumento das distâncias-tempo, a perda de tempos de lazer e recreio, não são suficientes para diminuir a apetência dos cidadãos pelo modus vivendi urbano.

A estrutura económica, o emprego, a acessibilidade à informação, a formação científica e técnico- -profissional, a oferta de equipamentos desportivos e culturais, a rede de transportes, a heterogeneidade social e cultural, continuam a ser factores preponderantes na escolha da localização para a maioria dos cidadãos.

Apesar de se sentir cada vez mais ameaçado pelas rupturas de equílibrio nos diversos susbsistemas de que depende, o Homem continua, na sua análise individual de custos-benefícios, a colocar claramente as cidades em primeiro lugar.

Aopção entre a oportunidade de "consumirrecursos naturais e funções urbanas" e o risco de vir a "ser consumido" pelo Ecossistema não é uma variável considerada na decisão de localização.

O argumento da "sobrevivência da espécie", como motivação para a implementação de uma política de desenvolvimento sustentável nos espaços urbanos, não tem condições para vingar porque, do ponto de vista prático, colide com um vastoleque de expectativas de aquisição de produtos e funções associadas a padrões de "qualidade de vida" superiores ${ }^{(1)}$.

O "conceito de qualidade" é portanto, muito relativo.

É a cultura da época que determina o "grau" e a "quantidade" mínima com que se atinge a plena satisfação, com um produto ou com uma função(2).

Assim, é natural que se façam sentir especialmente nas cidades, as várias rotas de colisão entre a "sustentabilidade do ambiente natural" e as expectativas de "qualidade de vida" dos cidadãos (Fig. 5).

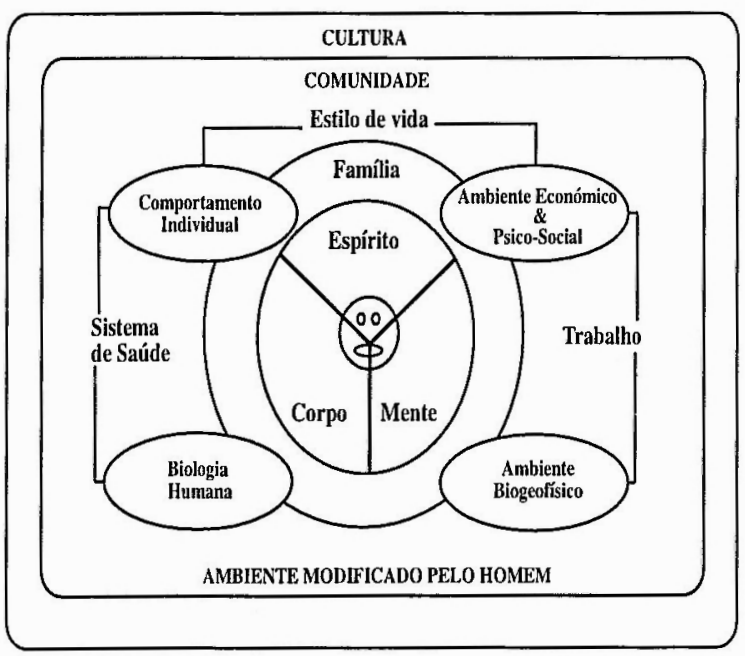

Fig. 5 - Elementos determinantes na definição do padrão de qualidade de vida e bem-estar de cada cidadão (adaptado de HANCOCK, 1985).

(1) Os exemplos de que a promoçāo da qualidade de vida nem sempre é um passo no sentido da sustentabilidade do ambiente natural são inúmeros $\mathrm{e}$ diversificados:

- prescindir do uso do automóvel individual em alguns dias da semana, em algumas horas do dia ou em certas áreas da cidade coarta a liberdade dos cidadãos de se movimentarem por onde querem e quando o desejam fazer; 
As expectativas de "qualidade de vida" de cada cidadão constroem-se a partir de uma mescla de registos provenientes da comunidade e da cultura vigente. Estes sinais exteriores vão sendo memorizados pelo indivíduo e doseadamente assimilados consoante a personalidade.

Embora as características da personalidade individual predominem, em muitos casos, sobre a influência dos padrões de comportamento, o estilo de vida ou o tipo de ambiente económico e psico-social da comunidade em que se inserem, os cidadãos não lhes são totalmente imunes.

Acreditamos, por isso, que a ideia de superioridade dos homens relativamente às outras componentes do ambiente, veiculada em grande parte pela tradição judaico-cristẫ ${ }^{(3)}$, contribuiu para inimputabilizar o Homem na maior parte dos cenários de insustentabilidade criados.

Propusémo-nos, a este propósito, o desafio de reler a Bíblia Sagrada, com o intuito de procurar entender e seleccionar os elementos essenciais, nela contidos que, socio-culturalmente fomos decantando ao longo dos séculos, e que continuam a marcar profundamente as nossas performances no Ecossistema.

Trata-se de princípios e conceitos que têm entravado, algumas vezes, a adopção de teorias, de hipóteses explicativas, de métodos ou de técnicas de compreensão da realidade mais rigorosas cientificamente, e mais adequadas aos registos provenientes da realidade.

\section{As relações homem-meio no pensamento judaico-cristão e na perspectiva (ecos)sistémica}

Ao lermos a Bíblia Sagrada, em busca de testemunhos daquele que tem sido, há mais de dois mil anos, o esteio orientador do pensamento de um grande número de habitantes da ecúmena (Anexo 1),

- diminuir o consumo de energia implica por vezes rejeitar o uso de equipamentos que promovem o conforto em áreas mais hostis;

- a imposição de taxas sobre a quantidade de resíduos sólidos urbanos (RSU's) recolhidos ou sobre os efluentes líquidos domésticos lançados para a rede de saneamento colide com as motivações consumistas que tipificam os padrões culturais vigentes. Há uma clara percepção, por parte dos cidadãos, de injustiça de "armadilha" neste tipo de penalização, ainda que a necessidade de custear as soluçōes de tratamento seja perfeitamente compreendida;

- a delimitação de áreas non edificandi nas áreas urbanizadas para permitir a criação de espaços de lazer e recreio, diminui a área útil disponível para construção e faz subir o preço do solo, contrariando a vontade dos cidadãos de residir nas áreas mais saudáveis da cidade.

(2) Segundo SMITH (1971), "...The desire for food is limited in every man by the narrow capacity of his stomach, but the desire for the conveniences and ornaments of building, dress, equipage, and household furniture, seems to have no limit or certain boundary..." (citado em O'RIORDAN, 1983, p.49), e segundo MISHAN (1973) quando afirma “...The rich corrupt themselves by practising greed, and corrupt the rest of the sociaty by provoking envy..." citado em O'RIORDAN, 1983, p.89.

(3) A tradição judaico-cristã serviu de âncora à maioria das sociedades ocidentais e serve-nos ainda como um importante quadro de referência. constatámos, com relativa facilidade, que a estrutura organizacional do mundo que traduz é determinante para compreender a forma como nos relacionámos com o ambiente natural (Fig. 6).

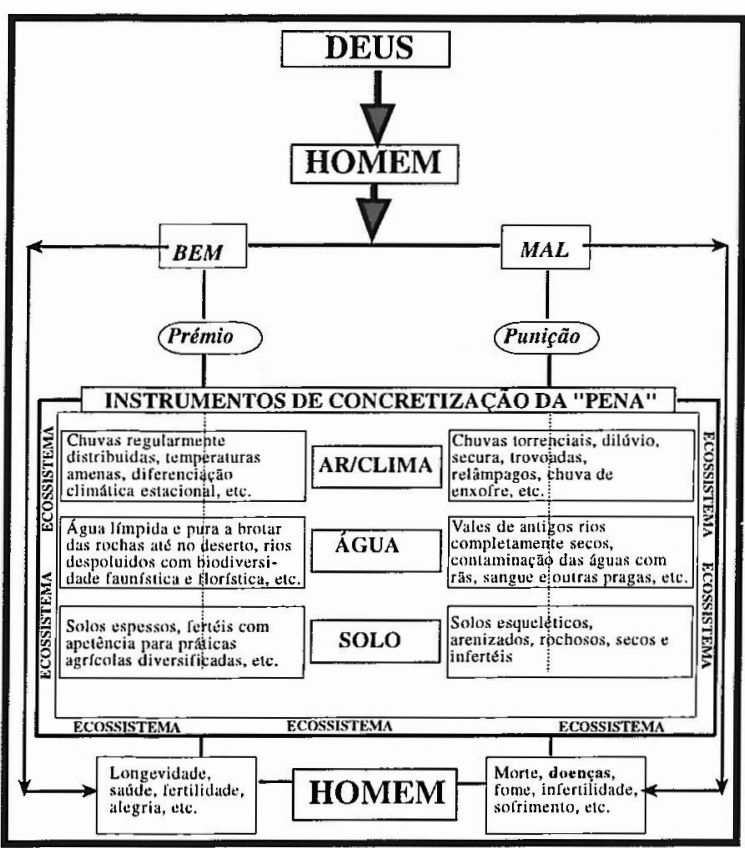

Fig. 6 - Arquitectura conceptual da organização do Planeta presente no pensamento judaico-cristão.

A arquitectura conceptual da organização doplaneta e dos mecanismos de retroactividade, presentes no pensamento judaico-cristão, assenta no poder absoluto de um ser superior - Deus - que disponibiliza oportunidades de "bem-estar" e de "qualidade de vida" ao Homem, consoante os seus procedimentos morais.

As componentes do Ecossistema (ar, água e solo), não passam de meros instrumentos de concretização de penas, inflingidas por uma entidade superior Deus - ao Homem, de acordo com o seu comportamento $^{(4)}$ (Fig. 6).

Nafilosofia judaico-cristã, oEcossistemaé, portanto, entendido como um conjunto de elementos que nos é exterior.

As interrelações vitais, neste quadro teórico, são entre Deus e o Homem (Fig. 6). Todas as outras componentes do Ecossistema existem e reagem sob a influência exclusiva e arbitrária da vontade de Deus.

Esta separação entre o Homem e as outras componentes do Ecossistema, não será crucial, para explicar o enorme sentido de impotência e desresponsabilização dos homens relativamente às suas acções sobre o suporte biogeofísico?

(4) WHITE, (1967), "...Christianity is the most anthropocentric religion the world has seen, it has only established a dualism of man and nature but has also insisted that it is God's will that man exploit nature for his proper ends..." citado em O'RIORDAN, 1983, p.203. 
Segundo a Bíblia Sagrada: primeiro, Deus criou o Ambiente Natural ${ }^{(5)}$ e, só depois, o Homem.

O Homem foi criado à semelhança de Deus e empossado do poder de dominar sobre "...os peixes do mar, sobre as aves do céu, sobre os animais domésticos e sobre todos os répteis..." (Anexo I, cit. iv).

Este domínio/poder sobre o Ambiente Natural não é, no entanto, absoluto. Deus exerce permanentemente um controlo sobre estas relações, doseando a quantidade, a diversidade e qualidade dos recursos naturais, que disponibiliza para premiar ou castigar os homens ${ }^{(6)}$.

Nas histórias bíblicas são frequentes os exemplos em que Deus recorre a fenómenos extremos da Natureza, utilizando-os como instrumentos de compensação ou de punição para atitudes e comportamentos dos intervenientes (Anexo 1 e Fig. 6).

O Homem é premiado com mais saúde, maior longevidade, fertilidade e alegria quando pratica o Bem (Anexo 1). Adoece, sofre, passa fome e morre quando age $\mathrm{Mal}$ (Anexo 1).

A entidade divina, severa e vingadora, não inflinge, contudo, as suas penas directamente sobre os indivíduosalvo. Aplica-as indirectamente, através de uma diversidade de cenários que vai criando.

Para elogiar o Bem, Deus propicia aos homens: luz, árvores agradáveis à vista, saborosos frutos, pastos, animais domésticos, reptéis e animais ferozes, água potável, chuva no seu tempo, etc. (Anexo $1 \mathrm{e}$ Fig. 6).

Para castigar o Mal, Deus flagela os homens com: dilúvios, chuvas de enxofre e de fogo, trovões, relâmpagos, neve, granizo, geada, pragas de moscas venenosas e gafanhotos etc.(Anexo 1 e Fig. 6).

De acordo com o pensamento cristão, é difícil relacionar os impactes ambientais (negativos e positivos), com a tipologia de atitudes e de acções antrópicas adoptadas.

A intensidade e a proporção do flagelo (catástrofe natural) ou da benesse (equílibrio e biodiversidade), não está de modo algum relacionada, com a gravidade ou o acerto da acção antrópica, exercida sobre qualquer dos recursos naturais (Fig. 6).

Compreende-se, portanto, que tenha sido fácil, para quem cresceu neste quadro de referência, acreditar na inevitabilidade do "sofrimento". Aprendeu a "aceitar" as catástrofes naturais (secas, cheias, poluição atmosférica, contaminação dos solos, etc). São penalizações que ocorrem, inesperadamente, e que não dependem do tipo de relação que estabelecemos com os outros elementos do Ecossistema, mas sim do modo como nos relacionamos moralmente com Deus.

(5) Segundo a Bíblia Sagrada Deus "..consíderou a Sua obra, muito boa...." (Anexo I, cit.v).

(6) Consoante o comportamento moral.
Resultou daí talvez, um progressivo alheamento do Homem relativamente às outras componentes do Ecossistema.

As atitudes de grande irreverência para com os recursos naturais banalizaram-se. A interpretação das relações de dependência Homem-Meio e sobretudo das "respostas" mais ou menos impulsivas do Ecossistema não ficou facilitada.

A difusão desta perspectiva do Ecossistema ${ }^{(7)}$ (Fig. 6) contribui claramente para desvalorizar a capacidade do Homem para encontrar modos de vida e organizações espaciais mais equilibradas e sustentáveis.

Todavia, tal só será possível se efectuarmos uma leitura integradora e sistémica do planeta (Fig. 7), onde o Homem esteja colocado, a par de todas as componentes ambientais, como co-participante no resultado final de um complexo sistema aberto (Fig. 7).

Multiplicaram-se, particularmente, na última década, os estudos de caso em que se demonstra, com suficiente clareza, a co-responsabilidade do Homem no acumular de "tensões" dentro do Ecossistema (Fig. 7).

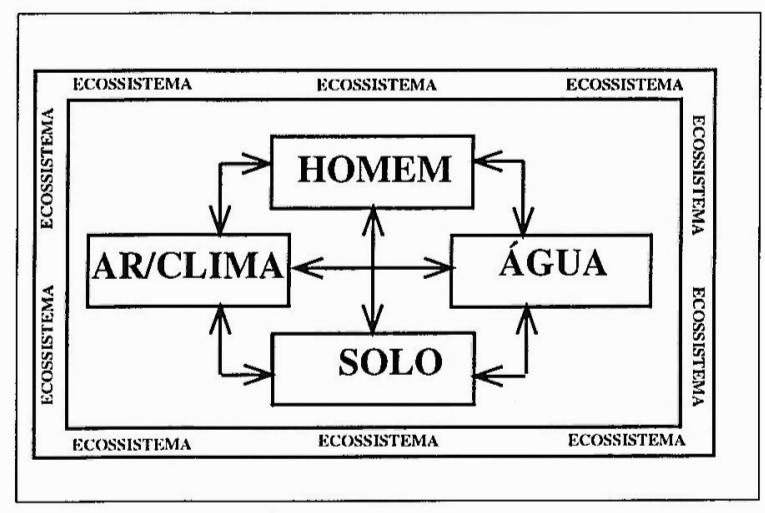

Fig. 7 - O Homem como elemento co-participante no complexo sistema aberto (Planeta).

\section{Conclusão}

É actualmente possível explicar a "contaminação das águas dos rios", o "aquecimento global", as "alterações climáticas provocadas pela urbanização", as "chuvas de enxofre", etc., sem precisar de recorrer à teia argumentativa do arbítrio divino entre o Bem e o Mal.

É relativamente fácil e vulgar identificar o Homem como um dos actores mais importantes na definição

(7) Por um lado, devido à forte componente irracional e empática que todas as correntes de pensamento religiosas possuem. Por outro, porque a investigação científica não encontrou ainda muitas das explicaçōes e justificações essenciais para compreender um vasto e diversificado conjunto de fenómenos com que os homens se confrontam quotidianamente. 
dos contornos, da intensidade e da magnitude dos impactes ambientais negativos diagnosticados.

Enquanto geógrafos, cabe-nos clarificar e comprovar experimentalmente, por exemplo, as relações de causalidade existentes entre:

- o Clima e o tipo de fenómeno urbano ${ }^{(8)}$;

- A Qualidade Quantidade dos Recursos Hídricos disponíveis e o tipo de ocupação do espaço urbano;

- A Geodinâmica Litoral e o tipo de processo de urbanização na orla costeira;

- Os Processos Erosivos e o tipo de uso do solo nas aglomerações urbanas.

Se enveredarmos por este tipo de abordagem geográfica dos ecossistemas urbanos, facilitaremos, indubitavelmente, a rendição dos mais optimistas e dos que subscrevem uma visão demasiado antropocêntrica do nosso papel, como parte integrante do Ecossistema, à validade da ideia, subjacente a este texto, de que tipos de organização espaço-funcional como o do Porto, representam o vértice de uma enorme pirâmide de ilusões de superioridade do Homem sobre o seu suporte ambiental, da qual nada beneficiaremos.

Só assim será possível, do ponto de vista teórico-metodológico, começar a carrear, para as práticas de planeamento, e para as expectativas de "qualidade de vida" e "bem-estar" dos cidadãos, as conclusões da investigação, efectuada em algumas áreas do saber, quanto às múltiplas relações de causalidade existentes no Ecossistema.

É, precisamente, esta perspectiva integradora do Homem no seu Meio, que nos conduzirá, enquanto geógrafos, a procurar, ao nível do espaço urbano, "indicadores de sustentabilidade" do meio e de "qualidade de vida" dos cidadãos.

Poderemos então demonstrar que a "saúde" e o "bem-estar" dos cidadãos residentes no Porto, não é fruto, pelo menos exclusivamente, do "destino" ou de um castigo, imposto por um ente superior, para expiar faltas morais (Fig. 6), mas que depende, substantivamente, da qualidade do ambiente urbano em causa.

Identificados os elos de causalidade tornar-se-á mais fácil imaginar medidas de política capazes de satisfazer simultaneamente a sustentabilidade do suporte biogeofísico e as expectativas de "qualidade de vida" e "bem-estar" dos residentes.

(8) Que já demonstrámos existirem, nomeadamente através da forma e da intensidade da "ilha de calor" (MONTEIRO, 1993).

\section{REFERÊNCIAS BIBLIOGRÁFICAS}

BLAIKIE, P., CANNON, T., DAVIS, I., WISNER, B., At Risk natural hazards, people's vulnerability and disasters. Routledge, London, 1994.

FARHAR-PILGRIM, Barbara, "Social Analysis", Climate Impact Assessment, KATES, R.W., AUSUBEL, J.H., BERBERIAN, M., (ed.), John Wiley \& Sons Ltd, Chichester, 1986.

HANCOCK, T., "The mandala of health: a model of the human ecosystem". Fumily and Community Health, nº, 1985, p.1-10.

HAUGHTON, Graham, HUNTER, Colin, Sustainable Cities. Regional Studies Association, Jessica Kingsley Publishers, London, 1996.

HOUGH, Michael, City form and natural process. Routledge, London, 1989.

INTERGOVERNMENTAL PANEL ON CLIMATE CHANGE, Climate Change 1995-the Science of Climate Change. WMO/ /UNEP, Cambridge University Press, Cambridge, 1996.

LINDZEN, Richard, "Global Warming: what we know and what we don't know", Ettore Majorana, 18th Seminar on Planetary Emergencies, 19-24 August 1993. Erice, Italy, 1993, polic.

McBURNEY, Stuart, Ecology into economics won't go or life is not a concept. Green Books, Cornwall, 1990.

MONTEIRO, Ana, O clima urbano do Porto - contribuição para a definição das estratégias de planeamento e ordenamento do território. FLUP, Porto, 1993, polic.

O'RIORDAN, T., Environmentalism. $2^{\mathrm{a}}$ ed., Pion Limited, London, 1983.

WHYTE, AnneV., "Perception", Climate Impact Assessment, KATES, R.W., AUSUBEL, J.H., BERBERIAN, M., (ed.), John Wiley \& Sons Ltd, Chichester, 1986. O'RIORDAN, T., 1983.

\section{Anexo I}

Alguns excertos da Bíblia Sagrada ilustrativos da perspectiva desresponsabilizadora do Homem enquanto actor no Ecossistema veiculada pelo Cristianismo

(i) “... No princípio, Deus criou os céus e a terra. A terra era informe e vazia. As trevas cobriam o abismo, e o espírito de Deus movia-Se sobre a superfície das águas....Deus chamou dia à luz e às trevas noite..." (pág. 17);

(ii) "... Deus disse: "Que a terra produza verdura, erva com semente, árvores frutíferas que deêm fruto sobre a terra, segundo as suas espécies, e contendo semente" (pág. 17); 
(iii) “...Deus disse:” Que a terra produza seres vivos, segundo as suas espécies, animais domésticos, répteis e animais ferozes, segundo as suas espécies" (pág. 18);

(iv) “...Deus, a seguir disse: "Façamos o homem à Nossa imagem, à Nossa semelhança, para que domine sobre os peixes do mar, sobre as aves do céu, sobre os animais domésticos e sobre todos os répteis que rastejam sobre a terra....Deus disse-lhes: "Crescei e multiplicai-vos, enchei e dominai a terra. Dominai sobre os peixes do mar, sobre as aves dos céus e sobre todos os animais que se movem na terra" (pág. 18);

(v) "...Deus, vendo toda a Sua obra, considerou-a muito boa" (pág. 18);

(vi) "...O Senhor Deus fez desabrochar da terra toda a espécie de árvores agradáveis à vista e de saborosos frutos para comer..." (pág. 19);

(vii) “...A seguir, disse ao homem:"...Nunca deveis comer o fruto desta árvore, maldita seja a terra por tua causa. E dela só arrancarás alimento à custa de penoso trabalho, em todos os dias da tua vida" (pág. 21);

(viii) "...pois vou lançar um dilúvio, que tudo inundando, eliminará debaixo do céu todo o ser animal, com sopro de vida" (pág. 25);

(ix) "...Erguia-se o sol sobre a terra, quando Lot entrou em Çoar. Então, o Senhor fez cair do céu sobre Sodoma e Gomorra uma chuva de enxofre e de fogo, enviada pelo Senhor. Destruiu estas cidades, toda a planície e todos os habitantes das cidades e até a vegetação da terra" (pág. 39);

(x) "...Eis o que diz o Senhor: para ficares a saber que eu sou o Senhor, vou ferir as águas do rio com a vara que tenho na mão e transformar-se-ão em sangue. Os peixes do rio morrerão, as águas do rio ficarão poluídas, e os egipcíos terão repugnância em beber a água do rio.

(xi) O Senhor disse a Moisés: Diz a Aarão: Toma a tua vara e estende a mão sobre as águas do Egipto, sobre os seus rios, sobre os canais, sobre as lagoas, sobre todos os seus reservatórios de água, para que se transformem em sangue. Haverá sangue por toda a terra do Egipto...Aarão levantando a vara, feriu as águas do rio, e todas as águas do rio se transformaram em sangue. Os peixes do rio morreram, as águas do rio ficaram infectadas e os egípcios não as podiam beber" (pág. 92);

(xii) "...flagelarei com rãs todo o teu território. O rio regurgitará de rãs; elas subirão para invadir a tua casa, o teu quarto, o teu leito..." (pág. 92);

(xiii) "...Aarão estendeu a mão com a vara, feriu o pó da terra, e os mosquitos cairam sobre os homens e os animais.Todo o pó da terra se transformou em mosquitos por todo o Egipto" (pág. 93);

(xiv) "...Lá não haverá moscas venenosas para saberes que Eu, o Senhor, estou presente nessa
terra....Surgiu na casa do Faraó e na dos seus servidores uma nuvem imensa de terríveis moscas, e todo o Egipto foi assolado pelas moscas venenosas" (pág. 93);

(xv) "...Moisés estendeu a sua vara para o céu, e o Senhor enviou trovões e granizo, e o fogo do céu caiu sobre a terra. O Senhor fez chover granizo sobre o Egipto. Choveu granizo e os relâmpagos misturavam-se ao granizo..." (pág. 95);

(xvi) “...O Senhor disse a Moisés:"Estende a mão para o céu e haja trevas sobre todo o Egipto, tão espessas que se possam apalpar" Moisés estendeu a mão para o céu, e durante três dias densas trevas cobriram todo o Egipto" (pág. 96);

(xvii) "...O povo começou então a murmurar contra Moisés, dizendo: "Que havemos de beber?". Moisés clamou ao Senhor, e o Senhor indicou-lhe um madeiro. Ele atirou-o à água e a água tornou-se potável.... Chegaram, depois a Elim, onde havia doze nascentes de água e setenta palmeiras. Acamparam ali, junto da água" (pág. 103);

(xviii) “...O Senhor disse a Moisés:”Vou mandar chover para vós pão do alto do céu. O povo sairá para recolher diariamente a quantidade necessária, a fim de o por à prova e ver se obedece ou não às Minhas ordens" (pág. 103);

(xix) “...Na manhã do terceiro dia, houve trovões, relâmpagos, uma espessa nuvem cobriu o monte e o som da trombeta retiniu com fragor. A multidão que se encontrava no acampamento tremia" (pág. 107);

$(\mathbf{x x})$ “...Entretanto, levantou-se um vento mandado pelo Senhor e trouxe codornizes do lado do mar, abatendo-se sobre o acampamento na extensão de um dia de caminho, de um lado e doutro, ao redor do acampamento, e a altura de cerca de dois côvados sobre o solo" (pág. 189);

(xxi) “...E o Senhor disse a Moisés:"Toma a tua vara e convoca a assembleia, tu e o teu irmão Aarão. Ordenareis ao rochedo, diante de todos, e ele dará as suas águas; farás brotar a água do rochedo e darás de beber à assembleia e seus rebanhos" (pág. 201);

(xxii) “...A terra que ides conquistar é um país de montanhas e de vales, impregnado das chuvas do céu. Uma terra que é objecto contínuo das atenções do Senhor, teu Deus: sobre ela os Seus olhos estão continuamente voltados desde o começo do ano até ao fim. Se obedecerdes às leis que hoje vos imponho a mando do Senhor, vosso Deus, servindo-O com todo o vosso coração e com toda a vossa alma, o Senhor derramará sobre a vossa terra a chuva no seu tempo, chuva de primavera e chuva de fim de outono, e farás a colheita do teu trigo, do teu vinho e do teu azeite.Fará crescer a erva no teu campo para o teu gado, e viverás na abundância" (pág. 239);

(xxiii) “...A voz do Senhor ressoa sobre as águas, o Deus da glória impera aos trovões, a voz do Senhor despede relâmpagos, a voz do Senhor abala o deserto 
de Cades, a voz do Senhor contorce os carvalhos, despe os bosques...O Senhor sentou-se em cima do dilúvio, e estabeleceu-se como rei eterno" (pág. 713);

(xxiv) “...Lamentações Sobre as Ruínas Do Templo:

Todavia, Deus é o meu rei desde sempre, o que leva a cabo as vitórias no meio da nação. Vós abristes o mar com o Vosso poder, esmagastes nas águas as cabeças dos dragões. Fizestes brotar as fontes e as torrentes, secastes os rios caudalosos. Vosso é o dia, e Vossa é a noite, criastes a luz e o sol, fixaste os limites à terra inteira, criastes o verão e o inverno..." (pág. 751);

(xxv) “...Deus E A História De Israel: Mandou-lhes trevas, e fez-se escuro; opuseram-se porém, às suas palavras. Converteu em sangue as suas águas, e matou todos os seus peixes. Encheu-lhes a terra de rãs, mesmo no interior dos palácios dos reis. Ordenou e vieram os insectos e mosquitos em todos os seus territórios. Em vez da chuva veio granizo, chamas de fogo sobre o país; devastou-lhes videiras e figueiras, destroçou as árvores dos campos. Deu a Sua ordem e vieram os gafanhotos e bruscos em grande quantidade, que lhes devoraram toda a verdura dos campos e comeram os frutos das suas terras..." (pág. 777);

(xxvi) “....Hino Ao Deus Libertador EProvidente: é Ele quem cobre os céus com as nuvens, e que prepara a chuva para a terra; é Ele quem faz crescer as ervas nas montanhas, e as plantas para o alimento dos homens; quem dá aos animais os seus pastos, e aos filhinhos dos corvos aquilo que pedem. Envia as suas ordens à terra, e a Sua palavra corre velozmente; faz cair a neve, branca como a lã, espalha a geada como cinza; faz descer o granizo aos punhados, e perante o Seu frio, quem pode resistir?" (pág. 808);

(xxvii) "... quando abriu o sexto selo, sobreveio um grande tremor de terra; o Sol tornou-se negro como saco de crina, a Lua tornou-se como sangue e as estrelas do céu cairam sobre a terra como os figos verdes caem da figueira sacudida por um vento forte. O céu retirou-se, como um livro que se enrola, e todos os montes e ilhas foram removidos dos seus lugares..." (pág. 1617);

(xxviii) "...Darei às minhas duas testemunhas o poder de profetizar durante mil duzentos e sessenta dias...Eles têm o poder de fechar o céu, a fim de que não chova durante os dias da sua profecia; têm poder sobre as águas para as converter em sangue e para ferir a terra com toda a espécie de flagelos; quando lhes aprouver" (pág. 1621);

(xxix) "...uma grande voz que dizia aos sete anjos: "Ide e derramai sobre a Terra as sete taças da ira de Deus... O segundo derramou a sua taça sobre o mar, que se converteu em sangue, semelhante ao de um morto; e morreram todos os seres vivos que estavam no mar...O terceiro derramou a sua taça nos rios e nas fontes e estas transformaram-se em sangue... O quarto derramou a sua taça sobre o Sol e foi-lhe permido queimar os homens com fogo...O sexto derramou a sua taça sobre o grande rio Eufrates: então as suas águas secaram, para abrir passagem aos reis do Oriente...O sétimo anjo derramou a sua taça no ar e saiu do Templo do Céu uma grande voz, vinda do trono, que dizia:"Está feito"! Houve então relâmpagos, vozes, trovões e um grande tremor de terra, tão grande como nunca tinha havido desde que há homens sobre a terra...Todas as ilhas fugiram e os montes desapareceram. Pedras de granizo, pesando cerca de um talento vindo do céu sobre os homens. E estes blasfemaram de Deus por causa do flagelo do granizo, pois esse foi terrível" (pág. 1627);

$(\mathbf{x x x})$ "...E eu declaro a todos os que ouvem as palavras da profecia deste livro:" Se alguém lhe acrescentar alguma coisa, Deus fará vir sobre ele os flagelos descritos neste livro; e, se alguém tirar alguma palavra do livro desta profecia, Deus tirar-lhe-á a sua parte da Árvore da Vida” (pág. 1633).

Fonte: Bíblia Sagrada, $14^{\mathrm{a}}$ edição, Difusora Bíblica (Missionários Capuchinhos), Lisboa, 1988, 1692 p. 